\title{
Sobre a prosa de Varlam Chalámov
}

\section{Andrea Zeppini Menezes da Silva ${ }^{1}$}

\begin{abstract}
This article aims to outline some features of Shalamov's prose by reading one of the stories of the work Kolyma Tales and two texts where the writer discusses his thoughts on literature and on his own work.
\end{abstract}

Keywords: Shalamov; literature; memory; testimony.

Resumo: Este artigo objetiva delinear alguns traços da prosa de Varlam Chalámov através da leitura de um dos contos da obra Contos de Kolimá e de dois ensaios em que o autor discute sobre o que pensa da literatura e de sua própria obra.

Palavras-chave: Chalámov; literatura; memória, testemunho.

\section{Apresentação}

Varlam Tikhonovitch Chalámov nasceu em 1907 e morreu em 1982. Em 1927, juntou-se a um grupo de jovens trotskistas quando estudava Direito na Universidade de Moscou, aos 20 anos. Preso em 1929, foi mandado para Solovki, um dos primeiros campos soviéticos, pertencente ao que viria a ser, algum tempo depois, o Gulag (Glavnóe Upravlenie Lagueréi, ou Direção Geral dos Campos). Sigla criada inicialmente para nomear os campos de trabalho da União Soviética, com o tempo passou a "designar todo o sistema soviético de trabalho escravo em todas as suas formas e variedades: campos de trabalho, campos de castigo, campos para delinquentes comuns e para presos políticos, campos para mulheres, campos para crianças, campos de trânsito" (Applebaum, 2006, p. 19).

Essa primeira prisão se deu por impressão de material ilegal, o chamado "Testamento de Lênin" ou "Carta ao Congresso", de 1922, texto em que o líder bolchevique critica e pede cautela diante do poder de um homem só (Toker, 2008). Solto em 1932, Chalámov foi preso novamente em 1937, quando foi mandado para Kolimá, condenado a cinco anos em campos de trabalho. Em 1943, sua pena foi prorrogada até o fim da guerra, o que aconteceu com muitos prisioneiros dessa época. Pouco depois, ganhou uma pena de mais dez anos, por dizer que Búnin era um “clássico"

\footnotetext{
${ }^{1}$ Doutoranda do programa de Cultura e Literatura Russa do Departamento de Letras Orientais da Faculdade de Filosofia, Letras e Ciências Humanas da Universidade de São Paulo (FFLCH/USP); bolsista Capes. E-mail: dedazeppini@ hotmail.com
} 
da literatura russa. Libertado em 1951, pôde retornar a Moscou apenas em 1953. Foi oficialmente "reabilitado" em 1956. No fim da década de 1970, já quase surdo (tinha a doença de Ménière), foi morar em uma casa de repouso para deficientes. Em janeiro de 1982, transferiram-no para uma instituição psiquiátrica, onde morreu dias depois. Sua obra mais importante é Contos de Kolimá, que começou a escrever assim que foi libertado e tem como base sua experiência nos campos. Memória, ficção, história. Literatura.

Varlam Chalámov é um escritor praticamente desconhecido no Brasil, com apenas dois de seus textos em tradução para o português: o conto "Xerez", presente na Nova Antologia do Conto Russo, de 2011, e o texto "Minhas Bibliotecas", que integra outra antologia de contos, dessa vez reunindo vários autores que escreveram sobre sua relação com os livros e com a leitura, A Paixão pelos Livros, de 2004.

Este artigo traz uma leitura do conto "Xerez", que faz parte dos Contos de Kolimá, em paralelo à leitura de dois ensaios sobre literatura do próprio autor, objetivando, dessa forma, o delineamento dos principais traços de sua prosa e de suas ideias sobre arte e literatura, sobretudo o que Chalámov acreditava ser uma "nova prosa". Neste artigo não há uma análise exaustiva do conto nem dos ensaios: o objetivo é apenas levantar alguns pontos trazidos por esses textos que contribuam para uma aproximação da obra deste autor por meio de suas concepções sobre arte e literatura.

Os dois ensaios são: "Sobre a Prosa", de 1965, que versa sobre a "nova prosa", categoria à qual pertenceria sua própria obra; e "Sobre a Minha Prosa", de 1971, em que Chalámov retoma muitos dos temas do ensaio anterior, tratando um pouco mais de sua própria obra e de seus métodos de trabalho. Esse texto é, na verdade, parte de uma carta escrita a Irina Sirotinskaia, amiga e editora do autor. São ensaios importantes como expressão do seu pensamento sobre a arte. "Xerez" é um conto que reúne muitos traços da obra de Chalámov, além de ser belíssimo. Suscita também a questão da relação entre a ficção e a memória, da verdade na arte, tema caro a Chalámov, que marca sua obra e sua concepção sobre literatura. Segundo o próprio autor diz em "Sobre a Prosa", o conto foi escrito em 1954, quando ele tinha acabado de ser libertado. Nesse período, escrevia dia e noite, tentando fixar no papel algo de importante, como ele diz, sobre o que vivera em seus anos de Kolimá. "Xerez" narra a morte do poeta Mandelstam, em um campo de trânsito, no final dos anos 1930, acontecimento que Chalámov não testemunhou.

\section{A "nova prosa"}


"O poeta estava morrendo." Esse é o início do quadro que começa a ser desenhado por Chalámov em "Xerez". Um homem morrendo no fundo de um beliche, no escuro, disposto entre muitos outros em fileiras duplas, uma lâmpada pendurada no teto por um arame. Um homem "de mãos grandes, inchadas pela fome, com dedos brancos e descorados, com unhas sujas e quase dobrando de compridas (...)”. A descrição do quadro é feita também por meio de pequenas ações do homem que está morrendo, trazendo para a cena uma sensação de instabilidade, fraqueza, debilidade. "De vez em quando os dedos das mãos se mexiam, estalavam como castanholas e tateavam um botão, uma casa, um buraco no casaco, espanavam algum cisco e paravam novamente." Pequenos detalhes que vão compondo a imagem, tornando-a vívida e transportando o leitor para esse lugar. "O poeta estava morrendo há tanto tempo que deixou de perceber que estava morrendo" (Chalámov, 2011, p. 573). O leitor é levado para um mundo que se esvai aos poucos, devagar, deixando-se embriagar pelo ritmo imposto pela morte.

Já nesse início é possível notar a relação de sua escrita com a descrição, aspecto tão importante na literatura realista do século XIX. Aliás, é um pouco com essa prosa que Chalámov debate em seus textos, com Tolstói e seus seguidores, reivindicando a necessidade de uma literatura feita em outros moldes. Pois bem, para Chalámov, a descrição deve ser econômica, sempre. O mínimo é descrito, só o que for necessário, para dar ao leitor a sensação do que se quer transmitir. Mais do que uma imagem visual, ao leitor é oferecida uma imagem de sensações, sentimentos. Para o escritor, a descrição da paisagem só deve existir se ela for simbólica, contribuindo como símbolo para a narrativa. Nesse conto, o leitor sente a falta de luz, imagina os beliches, o homem que está deitado morrendo. Além disso, as sensações. A importância do detalhe é outra característica do escritor. Nesse primeiro trecho do conto, já aparecem pequenos detalhes, insignificantes, mas que dão o tom do quadro geral e reforçam a sensação de instabilidade e fraqueza: os dedos que tateiam em busca de um botão, a mão que se movimenta a esmo, tira um cisco da roupa, sem necessidade. O detalhe é uma forma de descrever. Sua importância está na força do símbolo.

Chalámov clama pela necessidade de uma "nova prosa", que interesse ao leitor que passou pela guerra, pela revolução, por Auschwitz. Enumera, em "Sobre a Prosa", algumas características que essa escrita deve ter: em primeiro lugar, a seriedade do tema é essencial; não se deve perder tempo com ninharias, mas com questões importantes para o leitor de seu tempo, que ainda procuraria na literatura respostas para as questões 
eternas. E respostas também, mais especificamente, sobre a tragédia do Gulag, já que quase todas as famílias russas perderam alguém nos campos ou nas prisões stalinistas. $\mathrm{E}$ tudo isso deve ser contado sem declamação. Outra característica para a qual o autor chama a atenção é a brevidade do texto. A prosa deve ser simples e clara, e deve trazer à tona o sentimento: só assim, segundo o autor, se poderia ressuscitar a vida. Para Chalámov, é essencial a relação da vida real com a literatura: nos tempos correntes, esta não pode mais se apoiar na invenção; o leitor estaria farto disso. A importância dos detalhes como símbolos para expressar o essencial e trazer os estados de alma, bem como a pureza de tons (emprestada dos pós-impressionistas, como Gauguin e Van Gogh, conforme ressalta o autor nos dois ensaios) e a eliminação de tudo o que for excessivo são características já citadas. Vamos encontrar, durante a exposição do conto, alguns desses aspectos.

Voltando ao conto, o escritor segue descrevendo os pensamentos que passam pela cabeça do poeta naqueles instantes finais. A certa altura, ele se lembra de que lhe roubaram o pão que estava sob sua cabeça: "E aquilo foi um revés tão terrível que ele estava pronto para discutir, xingar, brigar, procurar e provar. Mas não tinha forças para tudo isso, e a ideia do pão enfraqueceu..." (Chalámov, 2011, p. 573). A vida não saíra ainda completamente do poeta: ele ainda tinha seus ímpetos, para arrefecer logo em seguida. Há quase que um ritmo de ondas, maré que vem e vai, como o mar, para onde o poeta, aliás, deveria ser levado, "mas o navio atrasara por algum motivo, (...) era bom ele estar ali" (Chalámov, 2011, p. 573). Ele está morrendo em um hospital de uma prisão de trânsito, de onde as pessoas eram levadas para os campos e algumas voltavam de lá.

A sensação é de lentidão, cansaço, embriaguez, morte. Nesses instantes finais, o poeta se lembra da vida. Mas não pensa na infância, na juventude ou no sucesso. Pensa no movimento do homem antes da morte. E pensa sem pressa, pela primeira vez: "A vida toda tivera de se apressar para algum lugar. É maravilhoso não precisar ter pressa, poder pensar devagar” (Chalámov, 2011, p. 573). E ele pensava na ciência, em Hipócrates, Freud, na relação com a morte. "E tudo estava em pé de igualdade: Hipócrates, o faxineiro com a grande pinta e a sua própria unha suja" (Chalámov, 2011, p. 574).

E, assim, "a vida entrava nele e saía, e ele ia morrendo" (Chalámov, 2011, p. 574). E, quando a vida voltava, vinham-lhe ideias. Pensa que vinha de um mundo onde é preciso devolver a vida às pessoas a todo instante, através de cafeína, glicose, 
respiração artificial, cânfora. Pensa que a morte era possível de ser evitada, sendo apenas um grande equívoco, ainda sem solução, mas um equívoco. Pensa que é possível a imortalidade. E pensa que não está cansado da vida, "nem mesmo agora, naquele hospital transitório, a "transitka". Sabia que esse era "o limiar do terror, mas não o próprio terror. Ao contrário, ali vivia o espírito da liberdade, e isso era sentido por todos". Ele estava, afinal, em um lugar de passagem, "na frente havia um campo, e atrás, uma prisão" (Chalámov, 2011, p. 574). Ali, diante da morte, no fundo escuro de um beliche, o poeta ainda sente o espírito da liberdade. Chalámov distingue o clima da prisão de trânsito da desumanização mais completa e brutal que o prisioneiro encontraria no campo. A certa altura, o poeta diz não se esquecer do sorriso cruel de um prisioneiro trazido dos campos, no meio de uma discussão encetada por presos que ainda não tinham conhecido esses lugares e se perguntavam o que seria pior: o campo ou a prisão. O sorriso do prisioneiro não deixa dúvidas.

O poeta pensa sobre a eternidade: se não era possível para seu corpo físico, poderia ser possível para sua arte. E começa a pensar em sua obra: entre as várias expressões que percorreu como escritor, sua arte encontrara algo novo e importante apenas na poesia. E percebe que "toda sua vida passada era literatura, livro, conto, sonho; e somente o dia de hoje era vida de verdade". Mas tudo isso lhe é indiferente já: pensa sem paixão. Fica admirado: "como podia pensar tanto em versos quando tudo já estava resolvido, e isso ele sabia muito bem, melhor do que qualquer um?" Mas "ele esperou... e entendeu" (Chalámov, 2011, p. 575). Como se, nesses instantes finais, a arte, a vida, o lugar de cada uma ficasse claro para o poeta. A eternidade existe: na arte. Nessa hora ele pensa em versos, porque, quando a vida vai embora, o que fica é a arte.

A arte e a vida. A ligação intrínseca entre essas duas instâncias é a essência da obra de Chalámov. No pensamento do escritor sobre a arte e principalmente sobre a "nova prosa", que é uma nova maneira de escrever, condizente com os tempos que correm, é muito forte a ideia da arte como proveniente da experiência própria do autor. A arte está ligada à vida: o escritor não é um espectador, um observador, mas alguém que vive na pele uma experiência, sobre a qual vai poder escrever. Em "Sobre a Prosa", ele critica a ideia de que seria prejudicial ao escritor se aproximar muito de seu material, como se isso tirasse o autor de seu eixo e o levasse a ter uma visão alterada dos fatos, distorcida. Pelo contrário, o escritor deve escrever sobre o que conhece, deve tirar a prosa de seu próprio sangue, seu material deve estar marcado em sua pele e em sua alma: o escritor deve ser Plutão, que volta do inferno, e não Orfeu, que desce ao inferno. Para 
Chalámov, em "Sobre a Prosa", é a experiência própria do autor que lhe dá o direito, e a obrigação moral também, de escrever.

Ainda que o autor deva conhecer intimamente aquilo que escreve, seu compromisso não é com o fato histórico, e sim com as marcas deixadas pelos fatos históricos em sua alma. Para Chalámov, o objetivo de sua arte é testemunhar o seu tempo. Uma espécie de obrigação moral. A arte deve tratar de temas importantes, como o escritor diz em "Sobre a Prosa", e que tema mais importante, em seu tempo, do que a morte e o perecimento de milhões de vidas humanas nos campos de trabalho de Stálin? Obrigação moral de testemunhar, em nome de todos os que não sobreviveram, de contar o que aconteceu para que essa história não seja esquecida. E também, ainda segundo Chalámov, testemunhar para responder às perguntas de quem ficou, mas perdeu nos campos de trabalho familiares e pessoas queridas. "Xerez" é um exemplo dessa necessidade: por meio da morte do poeta, Chalámov testemunha sobre milhares de mortes ocorridas nos campos de Stálin e contribui para que essa história não seja esquecida. Em "Sobre a Minha Prosa”, ele designa ainda outra função para sua literatura: uma bofetada na cara do stalinismo.

Para Chalámov, o leitor de seu tempo não se satisfaria mais com a ficção, como já foi mencionado. Não depois de passar por uma revolução, pela guerra, por Auschwitz, Hiroshima, Kolimá. Esse leitor precisaria de uma nova literatura. Não caberiam mais as grandes narrativas do século XIX, com o desenvolvimento de heróis, discursos individuais, histórias e conflitos inventados. Nos dois ensaios, Chalámov ressalta que seus contos tratam de pessoas que nunca tinham sido nem se tornaram heróis. Mártires. Pessoas sem biografia, sem passado e sem futuro. O que caberia agora seria a narrativa curta, fragmentos. Agora, o leitor precisa da verdade. Se ainda busca respostas para as grandes questões humanas na literatura, precisa ler histórias sobre a vida real. Segundo Chalámov, em "Sobre a Prosa", o leitor não se identifica mais com personagens de romances, como Julian Sorel, Rastignac ou Bolkonski, mas com pessoas reais. É por elas que o novo leitor mede seus atos. O escritor ressalta também que o grande interesse do leitor de seu tempo pelos livros de memórias seria um sinal tanto do interesse pela literatura quanto da necessidade da verdade: esse leitor se sentiria enganado ao ler um romance. Só a vida real poderia satisfazer esse público.

Nos dois ensaios, o escritor enfatiza o objetivo de sua arte: mostrar uma realidade desconhecida, um tema completamente novo, apesar da vasta literatura sobre prisões existente. Sua prosa seria uma investigação artística sobre a representação de 
novos padrões psicológicos, sobre estados do homem em situações extraordinárias, nunca vividas nem na alma nem na história. Ele tenta entender as pessoas vivendo no limiar imposto pelos campos de trabalho, limiar entre o humano e o não humano. A luta contra o mundo, contra a repressão do Estado, contra si mesmo. A vida humana sob condições desumanas: o que de humano resta? O que diferencia o homem do animal nessas condições? É isso o que investiga Chalámov, que diz, em "Sobre a Prosa”, que o homem é mais forte do que o animal: este não consegue carregar a carga de sofrimento e cansaço produzida pelo trabalho humilhante de Kolimá. Os animais morriam bem antes, se submetidos às mesmas condições dos homens.

O poeta do conto está nessa situação-limite. Está morrendo de inanição, caiu nas garras do Estado e foi submetido a condições desumanas de vida. Mas ainda pensa, sente, é um poeta morrendo, um homem, até o fim. Como escreve em "Sobre a Prosa", Chalámov acredita que, apesar de todo o horror que experimentou e que descreve em seus contos, em algum lugar, no fundo de seu ser, o homem ainda permanece homem, ainda resta um centelha de autonomia, de humanidade, para que ele possa dispor de seu destino, mesmo que num grau mínimo. Nem que seja apenas isso, uma centelha, que se concretiza nas páginas sobre a morte do poeta: ele ainda pode pensar, sentir, entender, isso ninguém conseguiu lhe tirar. Não é ódio, não é revolta o que vemos desprender-se das páginas do conto, mas uma espécie de aceitação, entendimento, busca pela humanidade.

Isso não significa que o campo possa ser positivo sob qualquer aspecto, como quiseram alguns autores (Soljienitsin, por exemplo). O campo não ensina nada de bom, afirma Chalámov com muita ênfase nos dois ensaios. O campo é uma escola negativa, do início ao fim. Nenhum homem deveria passar por tal experiência, é terrível desde a primeira até a última hora. E deixa sua marca em todos os que passam por ele, a marca da depravação, da corrupção, do mal. Chalámov afirma que quem passou pelos campos e sobreviveu nunca vai passar sequer um dia da vida sem se lembrar deles, do frio, do trabalho humilhante e exaustivo, da fome, de todo o resto.

Há um trecho, no texto "Sobre a Prosa", em que Chalámov cita uma conversa que teria tido na redação de uma revista de Moscou, onde é questionado justamente sobre "Xerez". É indagado sobre a "lenda" que escrevera a respeito da morte de Mandelstam. E o autor afirma que o que escreveu é verdade. Não, ele não testemunhou, não viu o poeta morrer. Mas estivera naquele mesmo lugar um ano antes do poeta, naquela mesma prisão de trânsito. E faz no conto, como diz, praticamente uma 
descrição clínica da morte por inanição. Essa morte, que é diferente de todas as outras, na qual a vida vem e vai e, durante cinco dias, não se sabe se a pessoa vai ou não morrer. Morte que ele parece ter testemunhado em outras ocasiões. Esse conto é verdade porque o poeta poderia ter sentido isso. É verdade porque o que está descrito no conto faz parte da experiência do próprio Chalámov.

A verdade que a arte deve guardar não é a realidade histórica, como já foi mencionado acima, mas é como essa realidade marcou o artista. A "nova prosa", como Chalámov chamava sua literatura e a arte necessária para o seu tempo, é a prosa que tem como material a marca da realidade no artista, cujo talento a transforma em arte. $\mathrm{O}$ escritor diz que esse conto foi escrito a propósito de Mandelstam, quase que como uma obrigação moral de homenagear o poeta, de não deixar passar em branco sua morte, de não deixar que o esquecessem, de tornar sua morte conhecida de todos. Mas, se foi escrito a propósito de Mandelstam, o conto é sobre ele mesmo, Chalámov. A verdade da arte é a verdade do artista. É seu sentimento, sua personalidade, sua alma. A "nova prosa" devolve à arte sua verdade porque está calcada na experiência.

Podemos relacionar essa "nova prosa" com a chamada "literatura de testemunho", a escritura possível depois das catástrofes do século XX, uma espécie de elaboração do luto, que se concretizou numa forma de escrita que começou a chamar a atenção após a Segunda Guerra e aparece como o "vértice entre a história e a memória, entre os fatos e as narrativas, entre, em suma, o simbólico e o indivíduo" (Seligmann, 2005, p. 82). O testemunho ampliaria o conceito de história para além da cientificidade. Ninguém duvidaria de sua "verdade", mas é uma "verdade" mais ampla e, talvez, subjetiva, do que a pretensa "verdade" histórica. Chalámov não nega a ficcionalização do fato: não esteve presente na morte do poeta, mas isso não impede que, para ele, seu relato seja "verdade". Após a Segunda Guerra, não caberiam mais as categorias universais, mas "o registro da memória - que é fragmentário, calcado na experiência individual e da comunidade, no apego a locais simbólicos e não tem como meta a tradução integral do passado" (Seligmann, 2003, p. 65). A literatura de testemunho leva a criação literária e a escrita da história a outros rumos.

O debate sobre a literatura de testemunho se fortalece a partir dos anos 1960, sobretudo em duas áreas: os debates sobre a Shoah nos Estados Unidos e na Europa, e o testimonio na América Latina. Ainda que a literatura de testemunho se refira mais a um forte teor testemunhal na escrita do que propriamente a um gênero literário, ela guarda peculiaridades que a coloca em um lugar separado na literatura. Escrever para elaborar o 
passado, para passar pelo luto, para exigir justiça, para que o presente se lembre dos que não sobreviveram para contar, uma obrigação moral de escrever: esses são aspectos muito fortes dessa literatura e aparecem na reivindicação de Chalámov por uma "nova prosa". Com as catástrofes do século XX, nascem uma nova literatura e uma nova maneira de contar a história e recuperar o passado: a experiência individual como base, a memória de quem viveu o que conta, de quem sofreu e, por isso, tem algo para contar.

"A vida entrava como uma senhora despótica: ele não a conhecia, e mesmo assim ela entrava em seu corpo, em sua mente: entrava como versos, como uma inspiração." Não há diferença aqui entre a vida e a arte. "E o significado dessa palavra pela primeira vez revelou-se a ele em toda sua plenitude. Os versos são aquela força revitalizadora que ele viveu. Precisamente isso. Ele não viveu por causa dos versos, ele viveu os versos" (Chalámov, 2011, p. 575). Nos momentos finais, o poeta descobre o significado da palavra "inspiração", algo que dá um sentido a tudo. Descobre sua humanidade, viva até o fim.

Chalámov não via nenhum sentido na vida ou na experiência do Gulag: para ele, tudo isso é absurdo, casual, acidental, sem sentido. As pessoas morrem ou se salvam por acaso. São presas ou ficam livres por puro acaso. Ele saiu vivo por acaso. Nos campos, tudo se dá por acaso - por sorte ou falta dela. Também para Chalámov, "tudo é apenas absurdo, cherry-brandy", como disse Mandelstam em poema de 1931. Assim, no absurdo da embriaguez da morte sem sentido, morreu o poeta de Chalámov, poeta até o fim. Mas há a criação de um sentido: esse sentido é a arte quem dá. O ideal artístico que se concretiza na narração da morte de um poeta: há algo maior que o Gulag, maior que qualquer atrocidade, maior que a morte.

Nos dois ensaios, dois aspectos da concepção de Chalámov sobre a arte são enfatizados: um é a verdade da arte, a arte apoiada na experiência, como foi dito acima. A transformação das marcas deixadas pela realidade na alma do artista, suas memórias, sentimentos, emoções, personalidade. O outro, que define a arte para Chalámov, é a forma. A memória por si não é arte: para se tornar arte, ela tem que vir à tona em uma forma artística. A forma que dá ao material bruto a inspiração, o talento do artista. Algumas características dessa forma já foram mencionadas acima: a descrição econômica da paisagem, a importância do detalhe, a simplicidade, a clareza, o corte de tudo o que for supérfluo. Para chegar a isso, existe um processo, que Chalámov menciona em seus ensaios. 
Esse processo se daria mais ou menos da seguinte maneira: em primeiro lugar, o autor tem que ter vivido o seu tema. O processo de lembrar é doloroso, mas é nele que se fundamenta a escrita. E a memória de Chalámov é um capítulo à parte: sua concepção de memória é algo quase físico, um lugar onde se guardam todos os acontecimentos, sentimentos, emoções de uma vida toda. Uma espécie de fita onde se registra tudo isso. Para o escritor, toda e qualquer experiência é passível de ser recuperada, basta que se tenham as condições adequadas.

A partir de sua experiência, o autor tem algo de importante a dizer e, em certo momento, a necessidade de compartilhar as conclusões tiradas pela vida é tão premente que ele precisa escrever. A escrita vem da necessidade de expressar, de compartilhar, de superar algo. Vem da necessidade de escrever: é algo vital. Então, o autor vai buscar um enredo. E isso é o que não lhe falta. Chalámov anotava em seu caderno as primeiras frases de contos que escreveria um dia. Para ele, a primeira e a última frase de um conto são essenciais ao processo: por elas se começa, sem elas não há conto. Para o trabalho da memória, é preciso a solidão. A espera, o apelo, o chamado ao interior do artista. A inspiração não vem todos os dias, mas só vem com muito trabalho. A criação se faz antes de as palavras chegarem ao papel: frases, metáforas, comparações chegam à página em branco já em sua forma final, vindas diretamente da fonte da memória.

A espontaneidade é algo muito prezado por ele. Faz parte da autenticidade, da verdade do artista, mas também da forma. A frase recebida pelo papel não deve ser retocada, corrigida, acabada. Sobre esse trabalho realizado em seu interior, o escritor não tem muito controle. Ele espera, procura memórias, se abre para elas, aceita o sofrimento trazido pelo lembrar, grita, chora, fala sozinho. Só se acalma depois de o conto estar pronto, ou pelo menos parte dele. Cada frase é falada. Chalámov ressalta em seus ensaios a importância da base sonora, do ritmo obtido em cada conto. Escrever, para ele, não é uma atividade puramente intelectual, mas parece mexer com todo o seu ser, com seu corpo, suas emoções sofridas. Processo dolorido, difícil. Porém necessário. Em "Sobre a Prosa", ele se lamenta por ter que despender suas energias para trabalhar justamente esse material. Mas, sem isso, não há superação possível.

Até o fim da vida, Chalámov só viu publicadas em seu país algumas coletâneas de versos. Alguns dos Contos de Kolimá saíram em samizdat (publicações não oficiais, datilografadas ou manuscritas, incluindo diversos temas, mas, sobretudo, publicações de escritores dissidentes proibidas pela censura) e depois foram para o exterior. Mas eram publicações sobre as quais Chalámov não tinha controle. E sofria muito com o fato de 
seus contos serem publicados como se fossem unidades esparsas, quando tinham um sentido dentro de um todo maior (o lugar de cada conto dentro de Contos de Kolimá era pensado; a ordem dos contos também narrava a história maior da experiência do artista, como ele conta em "Sobre a Prosa"), e sofria também com o fato de serem corrigidos e alterados. Para o escritor, o erro faz parte da verdade do artista. Se houver erros no modo como a memória, o sentimento, a personalidade do escritor se expressaram, isso faz parte da verdade e da autenticidade: faz parte da forma. "Agora estava tão visível, tão sensivelmente claro, que a inspiração é que era a vida; diante da morte foi-lhe permitido saber que a vida era inspiração, precisamente a inspiração" (Chalámov, 2011, p. 575). A vida é inspiração. A vida também erra, titubeia, respira, procura.

E quanto mais o tempo passa, ali, naquele fluir e refluir da vida, fica mais clara para o poeta a ligação entre a arte e a vida: "a vida toda entrava de forma suave nos versos e ali se dissolvia comodamente. E assim devia ser, pois os versos são palavra" (Chalámov, 2011, p. 575). Como se a vida fosse cedendo espaço, não para a morte, mas para a essência da arte. Ali, prestes a morrer, o poeta continuava seu ofício. "As estrofes agora também se levantavam, uma após a outra, e embora há tempos ele não anotasse nem pudesse anotar seus versos, todas as palavras se levantavam facilmente, num certo ritmo indicado e a cada hora inusitado." As palavras lhe vinham fáceis, sem esforço, "cada palavra era uma parte do mundo, elas atendiam à rima, e todo o mundo passava com a rapidez de uma máquina eletrônica" (Chalámov, 2011, p. 575). É o processo de escrita, ideal, descrito por Chalámov em seus ensaios, colhendo o fruto de uma vida toda de trabalho e dedicação: as palavras fluem, estão vivas, a vida passa a existir em sua essência, que é fazer poesia.

Era tudo tão fácil que não era preciso buscar as palavras, mas repeli-las. Como se nele existissem dois homens: o que compõe e o que seleciona. "E ao ver que ele são os dois homens, o poeta entendeu que agora estava compondo versos verdadeiros." $\mathrm{O}$ poeta vai se aproximando de uma essência da arte. Pergunta-se por que os versos não eram anotados. "Anotar, publicar: tudo isso é mera vaidade. Tudo o que nasce por interesse não é o melhor." A arte está em outro lugar: "O melhor é o que não foi anotado, que foi composto e desapareceu, que se dissipou sem deixar rastro; e somente a alegria criadora, que ele percebe e que não se pode misturar com nada, mostra que o poema foi criado, que o belo foi criado" (Chalámov, 2011, p. 576). Como se a morte do poeta fosse tirando da arte tudo o que é supérfluo, deixando apenas o que é vivo e necessário: sua pureza. 
A vida lhe escapa novamente e o poeta fica durante muitas horas parado, sem pensar em nada. Quando volta a si, vê à sua frente "uma espécie de alvo de artilharia ou mapa geológico" (Chalámov, 2011, p. 576). E demora a se dar conta de que eram seus próprios dedos. Como se seu corpo já lhe fosse um estranho, já não lhe pertencesse mais: a morte se aproximava, lenta e inexoravelmente. O poeta se lembra de um chinês de sua infância, que lhe pegou na mão e lhe vaticinou um grande futuro: ele era um menino felizardo. Mas nada disso importava mais. O poeta estava morrendo.

E se pergunta o que será morrer como um poeta. Começa a pensar no que o espera. "Sim, ele adivinhava algo daquilo que o esperava adiante. Na passagem, teve tempo de entender e adivinhar muita coisa. E ele ficou alegre, ficou alegre em silêncio por sua impotência, e esperava morrer" (Chalámov, p. 577, 2011). A vida ainda continuou no seu ir e vir. Ele sentiu vontade de comer, mas não tinha o quê. As horas passaram, a manhã chegou, e com ela as bandejas com pães. Mas ele já não se importava, até que lhe deram sua cota diária.

E, então, a indiferença que o dominara até aquele momento foi substituída por uma fome, uma gana, algo feroz naquele corpo já quase sem vida, uma recusa à morte. Já não há mais vestígio da embriaguez que dá o tom a todo o conto: "Ele mordia o pão com seus dentes infeccionados; as gengivas sangravam, os dentes quase caíam, mas ele não sentia a dor. Apertava o pão contra a boca com todas as forças, enfiava-o na boca, mordia-o, rasgava, roía...” (Chalámov, 2011, p. 576). Como se fosse um último apelo, um agarrar-se à vida, algo maior que ele, humano e mais que humano, a vida que queria viver. Até que os vizinhos o detiveram: era sempre melhor deixar um pouco para comer depois. Ele morreu naquela mesma noite. Seus vizinhos ainda conseguiram esconder sua morte durante dois dias para pegar sua cota diária. Chalámov desenha um quadro terrível, tocante, pungente. Sem alarde, sem grandiloquência, sem "literatices".

\section{O novo artista}

A visão de Chalámov sobre arte e literatura, como esta aparece nos dois ensaios trazidos para este artigo, revela uma tensão entre a espontaneidade do artista, entendida por ele como verdade, e a forma artística. Essa tensão parece ser resolvida na necessidade de testemunhar, de escrever.

Para Chalámov, escrever vem de uma necessidade, de um desejo, que é quase obsessão. É sua experiência que lhe dá o direito de escrever e de julgar. É o sofrimento 
que sentiu na pele. Em “Xerez”, é o sofrimento de Chalámov que está em cena. Por isso, esse conto é uma verdade histórica para o escritor. Mas não seria arte se não tivesse passado pelo filtro do talento. A lembrança da prisão de trânsito, da morte por inanição, do cotidiano do campo, da ração de pão, do roubo da ração de pão, da água fervendo que distribuem dizendo que é chá, do artifício de esconder dos guardas a morte de um prisioneiro para continuar recebendo sua ração por mais um tempo, do desespero quando não sobram cascas de pão para comer mais um pouquinho, das fileiras de beliches, da pinta do faxineiro, do ir e vir da morte por inanição, de tantos detalhes que aparecem no conto, nada disso seria arte se não houvesse o talento para dar-lhes uma forma. A memória se transmuta em arte quando encontra uma forma narrativa. Chalámov chama a atenção para isso em "Sobre a Minha Prosa": não basta colecionar fatos, como faziam nos anos 1920 os artistas da vanguarda de esquerda, imbuídos do construtivismo e apostando na "literatura do fato", pensando a literatura a serviço da revolução. Para Chalámov, um fato é arte quando passa pela carne e pelo sangue do artista e é devolvido ao mundo em uma nova forma narrativa. Por isso, a arte deve tratar de temas importantes, essenciais para o homem. Essa é a "nova prosa" de Chalámov, que se diz "cronista de sua própria alma", em "Sobre a Minha Prosa". É isso o que o novo artista deveria ser.

\section{Referências bibliográficas}

Applebaum, Anne. Gulag, Historia de los Campos de Concentración Soviéticos. Barcelona: Debolsillo, 2006.

Chalámov, Varlam. "Xerez" (tradução de Nivaldo dos Santos). In: Gomide, Bruno Barreto (org.). Nova Antologia do Conto Russo. São Paulo: Editora 34, 2011. O Prose (Sobre a Prosa). 1965.

http://www.shalamov.ru/library/21/45.html O Maiei Prose (Sobre a Minha Prosa). 1971.

http://www.shalamov.ru/library/21/61.html . "Minhas bibliotecas" (tradução de Tatiana Larkina). In: Silveira, Julio; Ribas, Marta (orgs.). A Paixão pelos Livros. Rio de Janeiro: Casa da Palavra, 2004.

Seligmann-Silva, M. “Testemunho e a Política da Memória: O Tempo Depois das Catástrofes". In: Projeto História (Revista do Programa de Estudos Pós-Graduados em 
História e do Departamento de História da PUC-SP) nº 30 (“Guerra, Império, Revolução"), junho 2005, 31-78.

(org.). História, Memória, Literatura. O Testemunho na Era das Catástrofes.

Campinas: Editora da Unicamp, 2003.

Toker, Leona. "Samizdat and the Problem of Authorial Control: the Case of Varlam

Shalamov". Poetics Today (2008) 29(4): 735-758.

http://poeticstoday.dukejournals.org/content/29/4/735.full.pdf+html 